\title{
FORMATION OF CUSPATE FORELAND IN FIELD SUBJECT TO WAVE-SHELTERING EFFECT OF ISLANDS
}

\author{
Takaaki Uda ${ }^{1}$, Masumi Serizawa ${ }^{2}$ and Shiho Miyahara²
}

\begin{abstract}
The morphological characteristics of the cuspate forelands located in Gardiners Bay on Long Island, New York, and Ukraine Bay in the Black Sea, and a land-tied island in Vietnam were investigated. The BG model (a model for predicting three-dimensional beach changes based on Bagnold's concept) was used to predict the development of a cuspate foreland, when an island is located offshore of the cuspate foreland and waves are incident from two opposite directions. It was found that a cuspate foreland elongates toward the lee of the island owing to the wave-sheltering effect of an island. The formation of a land-tied island when five islands and two sand sources are located on opposite shores was also predicted using the BG model.
\end{abstract}

Keywords: cuspate foreland; numerical simulation; BG model; Ukraine Bay; Gardiners Bay

\section{INTRODUCTION}

A sand spit is a dynamically changing type of topography protruding into the sea and is formed by the successive deposition of sand by longshore sand transport under the conditions that waves are obliquely incident at a large angle relative to the direction normal to the shoreline and a sufficient volume of sand is supplied from the upcoast (Zenkovich 1967). A cuspate foreland is another type of topography protruding into the sea, similarly to the sand spit, and is formed when waves are incident to a sandy beach from two opposing directions. Ashton et al. (2001) and Ashton and Murray (2006) developed a model for predicting the development of cuspate forelands with rhythmic shapes under the condition that waves are obliquely incident from two opposing directions at an angle larger than approximately $45^{\circ}$ relative to the direction normal to the shoreline. Serizawa et al. (2012) and Uda et al. (2014) also proposed a model for predicting the topographic changes of cuspate forelands of rhythmic shapes using the BG model (a three-dimensional model for predicting beach changes based on Bagnold's concept). However, there are few studies on the formation of a cuspate foreland under the condition that waves are incident from two completely opposing directions. Miyahara et al. (2014) studied the mechanism of the formation of a land-tied island as a result of the elongation of a cuspate foreland using the BG model. In their model, a wave field was evaluated by the angular spreading method for irregular waves, and a sand transport equation evaluated at the breaking point was employed. Serizawa et al. (2015) improved the model by which waves from two opposing directions are strictly solved using the energy balance equation to precisely evaluate the wave field. They studied the morphological characteristics, taking the two cuspate forelands of Futtsu Point and the one located at the northeast end of Graham Island in British Columbia, Canada, as examples. Then, a model for predicting the development of a cuspate foreland under the natural condition was proposed for waves incident from two opposing directions using the BG model. In the field, there are many cases in which a cuspate foreland is subject to the wave-sheltering effect of an island, but the deformation of the cuspate foreland has not yet been studied. In this study, we aim to develop a model for predicting the deformation of a cuspate foreland in the presence of islands.

\section{EXAMPLES OF DEVELOPMENT OF CUSPATE FORELAND IN FIELD WITH ISLANDS}

\section{Cuspate Forelands in Gardiners Bay on Long Island, New York}

Many cuspate forelands can be seen on the east end of Long Island, New York. Figure 1 shows the cuspate forelands formed at the tips of the islands in Gardiners Bay. Cuspate forelands A and B of 1.3 and $3.3 \mathrm{~km}$ lengths are formed at the north and south ends of Gardiners Island, respectively. In addition, sand spit $\mathrm{C}$ of $1.8 \mathrm{~km}$ length extends at Cedar Point in the south part together with another cuspate foreland of $2.6 \mathrm{~km}$ length extending southwestward at Orient. Because these cuspate forelands or the sand spit have water bodies on both their sides, they were assumed to be formed by waves incident from two opposing directions. Cuspate forelands A, B, and D are considered to have the same mechanism of development as the cuspate foreland that extended at the northeast end of Graham Island investigated by Serizawa et al. (2015) because of the resemblance between these cuspate forelands.

\footnotetext{
${ }^{1}$ Head, Shore Protection Research, Public Works Research Center, 1-6-4 Taito, Taito, Tokyo 110-0016, Japan

${ }^{2}$ Coastal Engineering Laboratory Co., Ltd., 1-22-301 Wakaba, Shinjuku, Tokyo 160-0011, Japan
} 


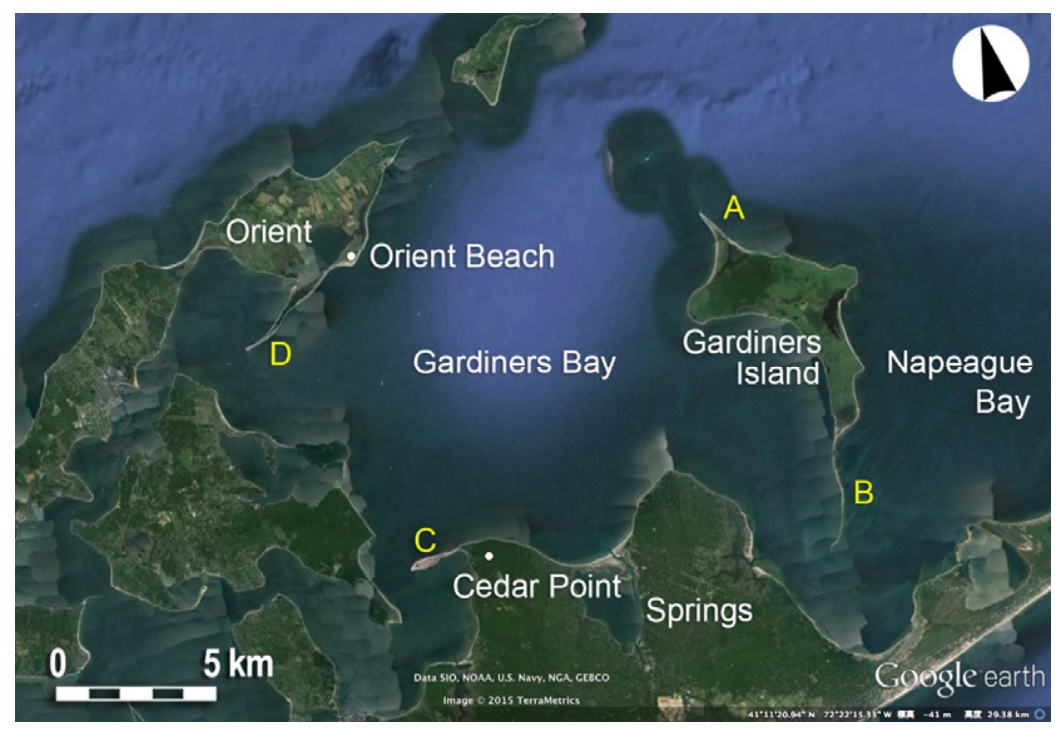

Figure 1. Location of four cuspate forelands in Gardiners Bay on Long Island.

\section{Cuspate Foreland on South Shore of Ukraine Gulf in Black Sea}

Ukraine Gulf extends eastward in the north part of the Black Sea, as shown in Fig. 2(a). The width in the north-to-south direction and the depth of this bay are 74 and $89 \mathrm{~km}$, respectively, and has a funnel shape with decreasing width to the east. A pair of sand spits have developed on the north and south shores. The length of the sand spit on the north shore is $41.7 \mathrm{~km}$, whereas that on the south shore is only $8.6 \mathrm{~km}$. The size of the north sand spit is one order of magnitude larger than that of the south sand spit. Furthermore, the angle of the direction of the shoreline in the middle of the north sand spit is $\mathrm{N} 101^{\circ} \mathrm{E}$, whereas that of the south sand spit is $\mathrm{N} 10^{\circ} \mathrm{E}$, i.e., both directions are approximately normal to each other. The changes in the size of the sand spit and the elongating direction are due to the predominance of the southerly waves because Ukraine Bay is located in the north part of Black Sea.

Figure 2(b) shows an enlarged satellite image taken around the south sand spit. This image shows that a slender barrier island extends alongshore while enclosing a lagoon behind it west of this promontory, whereas on the east side, many beach ridges are formed by the successive deposition of sand, transported from the eastern coast. Thus, it is clear that this promontory has been formed by the action of wind waves from the east and west sides, and hence it is called a cuspate foreland instead of a simple sand spit. In addition, an island of $1.05 \mathrm{~km}$ length and $0.56 \mathrm{~km}$ width is located offshore of the cuspate foreland, and the tip of the cuspate foreland tends to elongate to the lee of this island. This example shows that the wave-sheltering effect of the islands may affect the extension of the cuspate foreland.

\section{Land-tied Islands and Cuspate Foreland on Hon Bip Island North of Nha Trang, Vienam}

Hon Bip Island is located in Van Phong Bay north of Nha Trang, Vietnam. In the vicinity of this island, a land-tied island and a cuspate foreland are formed, similarly to the cases on Yoshima Island offshore of Shodo Island, as reported by Miyahara et al. (2014). Figure 3 shows a satellite image of Hon Bip Island. A shallow sea extends on the southwest side of this island, and slender islands of 0.7 and $1.07 \mathrm{~km}$ lengths exist, and sand bars of 0.53 and $0.20 \mathrm{~km}$ lengths connecting the islands extend to form a land-tied island. Furthermore, from the southwest end of the islands, a small-scale cuspate foreland extends westward. As mentioned above, if there is an island in the water body where the cuspate foreland is formed, it may be drawn to the lee of the island owing the wave-sheltering effect of the island. However, the formative mechanism of the cuspate foreland has not been studied, while also considering the wave-sheltering effect of the island.

\section{NUMERICAL MODEL (BG MODEL)}

We use the Cartesian coordinates $(x, y)$ and consider that the elevation at point $Z(x, y, t)$ is a variable to be solved, where $t$ is time. The beach changes are assumed to occur between the depth of closure $h_{c}$ and the berm height $h_{R}$. The BG model proposed by Serizawa et al. (2012) was used to predict the beach changes. The fundamental equation is given as follows. 
(a) Ukraine Gulf in Black Sea

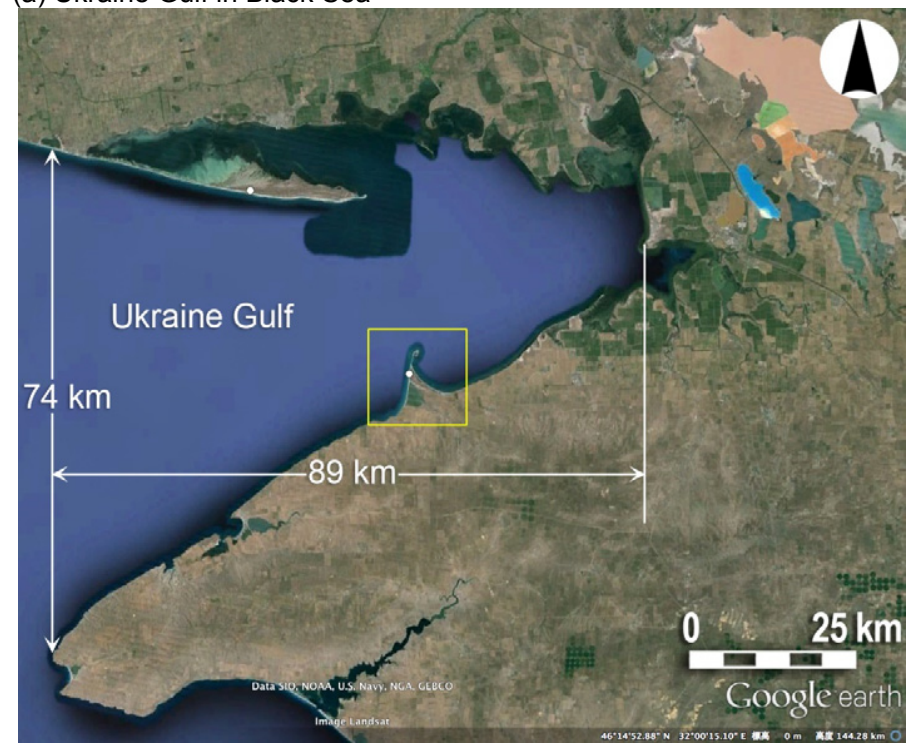

(b) Cuspate foreland on south shore of Ukraine Gulf

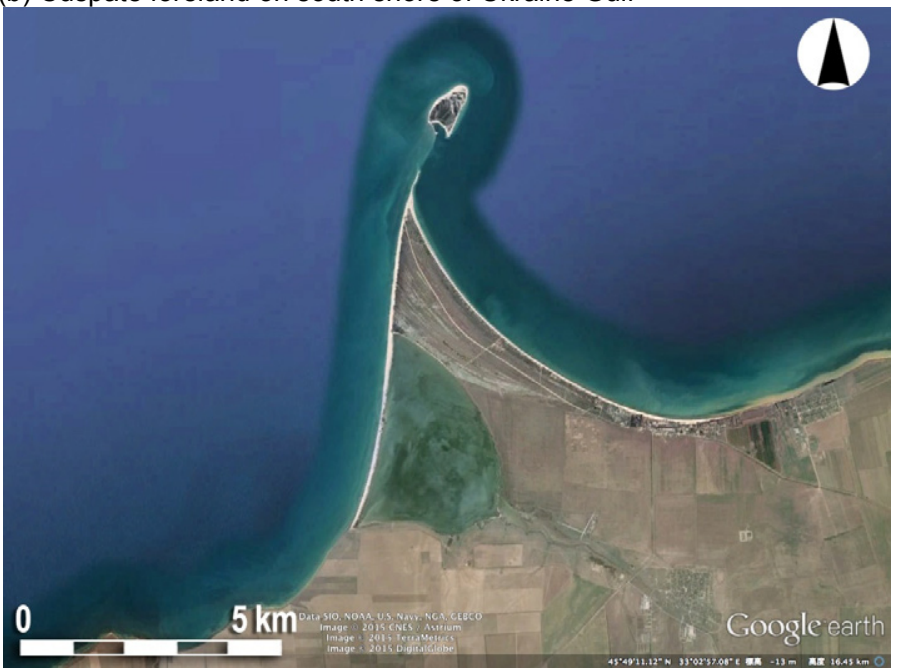

Figure 2. Development of cuspate foreland on south shore of Ukraine Gulf in Black Sea.

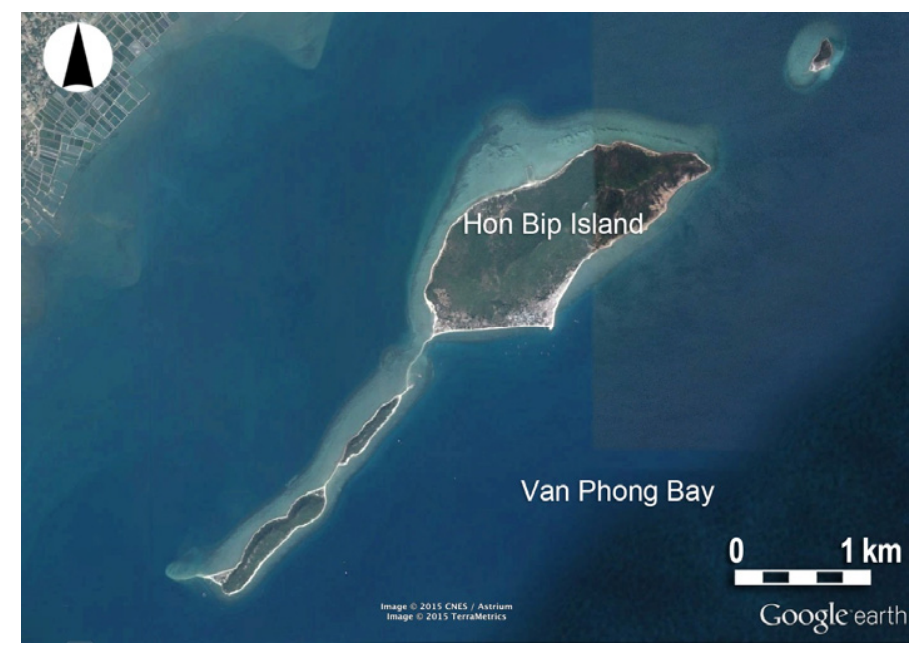

Figure 3. Hon Bip Island in Van Phong Bay in Vietnam. 


$$
\vec{q}=C_{0} \frac{P}{\tan \beta_{\mathrm{c}}}\left\{\begin{array}{l}
K_{n}\left(\tan \beta_{c} \overrightarrow{e_{w}}-|\cos \alpha| \overrightarrow{\nabla Z}\right) \\
+\left\{\left(K_{s}-K_{n}\right) \sin \alpha-\frac{K_{2}}{\tan \bar{\beta}} \frac{\partial H}{\partial s}\right\} \tan \beta \overrightarrow{e_{s}}
\end{array}\right\} \quad\left(-h_{c} \leq Z \leq h_{R}\right)
$$

Here, $\vec{q}=\left(q_{x}, q_{y}\right)$ is the net sand transport flux, $Z(x, y, t)$ is the seabed elevation with reference to the still water level $(Z=0), n$ and $s$ are the local coordinates taken along the directions normal (shoreward) and parallel to the contour lines, respectively, $\overrightarrow{\nabla Z}=(\partial Z / \partial x, \partial Z / \partial y)$ is the slope vector, $\overrightarrow{e_{w}}$ is the unit vector of the wave direction, $\overrightarrow{e_{s}}$ is the unit vector parallel to the contour lines, $\alpha$ is the angle between the wave direction and the direction normal to the contour lines, $|\cos \alpha|=\left|\overrightarrow{e_{w}} \bullet \overrightarrow{\nabla Z}\right| /|\overrightarrow{\nabla Z}|$, $\tan \beta=|\overrightarrow{\nabla Z}|$ is the seabed slope, $\tan \beta_{c}$ is the equilibrium slope, and $\tan \beta \overrightarrow{e_{s}}=(-\partial Z / \partial y, \partial Z / \partial x)$. Moreover, $K_{s}$ and $K_{n}$ are the coefficients of longshore and cross-shore sand transport, respectively, $K_{2}$ is the coefficient of the term given by Ozasa and Brampton (1980), $\partial H / \partial s=\overrightarrow{e_{s}} \cdot \overrightarrow{\nabla H}$ is the longshore gradient of the wave height $H$ measured parallel to the contour lines, and $\tan \bar{\beta}$ is the characteristic slope of the breaker zone. In addition, $C_{0}$ is the coefficient transforming the immersed weight expression into a volumetric expression $\left(C_{0}=1 /\left\{\left(\rho_{s}-\rho\right) g(1-p)\right\}\right)$, where $\rho$ is the density of seawater, $\rho_{\mathrm{s}}$ is the specific gravity of sand particles, $p$ is the sand porosity, and $g$ is the acceleration due to gravity).

The intensity of sand transport, $P$, in Eq. (1) is assumed to be proportional to the wave energy dissipation rate, as described by Serizawa et al. (2006), on the basis of the energetics approach of Bagnold (1963). $P$ is determined by the wave energy dissipation rate due to wave breaking at a local point, $\Phi_{\text {all }}$ (Eq. (2)), which can be determined from the calculation of the wave field.

$$
P=\Phi_{\text {all }}
$$

For the calculation of the wave field, the numerical simulation method with the energy balance equation given by Mase (2001), in which the directional spectrum of irregular waves is the variable to be solved, was employed with the additional term of energy dissipation due to wave breaking proposed by Dally et al. (1984), similarly to that reported by Serizawa et al. (2012). In this numerical simulation, the effects of wave refraction, wave breaking, and wave sheltering by the cuspate foreland itself are included. $\Phi_{\text {all }}$ in Eq. (2), which defines the sum of the energy dissipation of each component wave due to breaking, was calculated from Eq. (3).

$$
\Phi_{\text {all }}=f_{D} E=K \sqrt{g / h}\left[1-(\Gamma / \gamma)^{2}\right] E \quad\left(f_{D} \geq 0\right)
$$

Here, $f_{D}$ is the energy dissipation rate, $E$ is the wave energy, $K$ is a coefficient expressing the intensity of wave dissipation due to breaking, $h$ is the water depth, $\Gamma$ is the ratio of critical wave height to water depth on a flat bottom, and $\gamma$ is the ratio of wave height to water depth, $H / h$. In addition, a lower limit was set for $h$ in Eq. (3), similarly to the work of Serizawa et al. (2012). The wave field was recurrently calculated every 10 steps of the calculation of beach changes. In the calculation of the wave field in the wave run-up zone, an imaginary depth was assumed, as similarly assumed by Serizawa et al. (2012). Furthermore, the wave energy at locations with elevations higher than the berm height was set to 0 . In the numerical simulation of beach changes, the sand transport and continuity equations $(\partial Z / \partial t+\nabla \bullet \vec{q}=0$ ) were solved on the $x-y$ plane by the explicit finite-difference method using the staggered mesh scheme. In estimating the intensity of sand transport near the berm top and at the depth of closure, the intensity of sand transport was linearly reduced to 0 near the berm height or the depth of closure to prevent sand from being deposited in the zone higher than the berm height and to prevent the beach from being eroded in the zone deeper than the depth of closure, similarly to the simulation by Uda et al. (2013).

\section{CALCULATION CONDITIONS}

By defining the Cartesian coordinates $(x, y)$, as shown in Fig. 4, a rectangular basin of 1.1 and 1.6 $\mathrm{km}$ lengths in the $x$ - and $y$-axes, respectively, was set as the calculation domain. The water depth is assumed to be constant at $4 \mathrm{~m}$, and a sandy beach with a crown height of $50 \mathrm{~m}$ and a beach slope of $1 / 20$ was set in a rectangular area between $x=-300$ and $300 \mathrm{~m}$, and between $y=0$ and $300 \mathrm{~m}$, as the 
initial mound for the sand source. The crown height of the sand source was set to be much higher than the berm height of $1 \mathrm{~m}$, so that a sufficient volume of sand for the elongation of a cuspate foreland is supplied to the coast. The incident wave height was assumed to be $1 \mathrm{~m}$, and waves were incident from the $-x$-axis (downward) and the $+x$-axis (upward) directions with the probability of occurrence of 0.5 . The wave direction was determined by a random number every 10 steps of the calculation of the topographic changes.

While keeping the incident wave conditions constant, the initial arrangements of the sand source and the islands were altered, as shown in Fig. 5. In Case 1, the elongation of a simple cuspate foreland was predicted as a reference for other cases. In Cases 2-4, an island of $300 \mathrm{~m}$ length was installed at $x=$ $0,-300$ and $-600 \mathrm{~m}$, respectively, while maintaining the same shape of the sand source as that in Case 1, to investigate the wave-sheltering effect of the island on the elongation of the cuspate foreland. This is a model of the elongation of a cuspate foreland to the lee of the island observed off the south shore of Ukraine Gulf, as shown in Fig. 2. In Case 5, the extension of the cuspate foreland between islands was predicted when five islands were arranged on different axes. The formation of the land-tied island and cuspate foreland at the tip of the island, as in the case around Hon Bip Island in Van Phong Bay, as shown in Fig. 3, was studied. Finally, in Case 6, another sand source was set on the shore opposite to that in Case 1. Figure 6 shows the wave height distribution around the island at the initial stage in Cases 3 and 4, when waves propagate upward or downward. In each case, a wave-shelter zone is formed on the lee of the island, but its wave-sheltering effect is significant when waves propagate downward because of the proximity of the wave-shelter zone to the sand source.

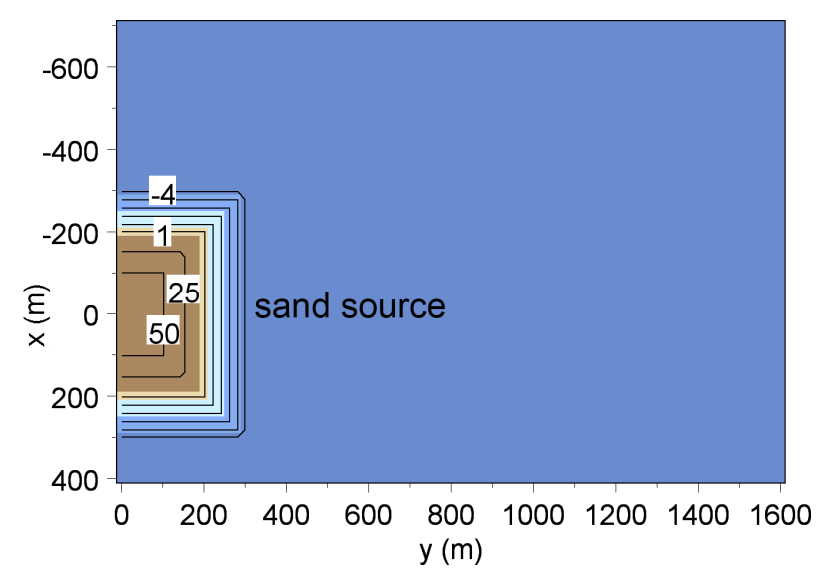

Figure 4. Definition of coordinate system.

\begin{tabular}{|c|c|}
\hline \multicolumn{2}{|r|}{ Table 1. Calculation conditions. } \\
\hline Wave conditions & Incident waves: $H_{l}=1 \mathrm{~m}, T=4 \mathrm{~s}$, wave direction $\theta_{l}=0^{\circ}$ and $180^{\circ}$ \\
\hline Berm height & $h_{R}=1 \mathrm{~m}$ \\
\hline Depth of closure & $h_{c}=4 \mathrm{~m}$ \\
\hline Equilibrium slope & $\tan \beta_{c}=1 / 20$ \\
\hline Coefficients of sand transport & $\begin{array}{l}\text { Coefficient of longshore sand transport } K_{s}=0.2 \\
\text { Coefficient of Ozasa and Brampton }(1980) \text { term } K_{2}=1.62 K_{s} \\
\text { Coefficient of cross-shore sand transport } K_{n}=K_{s}\end{array}$ \\
\hline Mesh size & $\Delta x=\Delta y=20 \mathrm{~m}$ \\
\hline Time intervals & $\Delta t=0.5 \mathrm{~h}$ \\
\hline Duration of calculation & $0.7 \times 10^{4} \mathrm{hr}\left(1.4 \times 10^{4}\right.$ steps $)$ \\
\hline Boundary conditions & Shoreward and landward ends: $q_{x}=0$, right and left boundaries: $q_{y}=0$ \\
\hline Calculation of wave field & $\begin{array}{l}\text { Energy balance equation (Mase, 2001) } \\
\text { - Term of wave dissipation due to wave breaking: Dally et al. (1984) model } \\
\text { - Wave spectrum of incident waves: directional wave spectrum density obtained } \\
\text { by Goda (1985) } \\
\text { - Total number of frequency components } N_{F}=1 \text { and number of directional } \\
\text { subdivisions } N_{\theta}=8 \\
\text { - Directional spreading parameter } S_{\max }=25 \\
\text { - Coefficient of wave breaking } K=0.17 \text { and } \Gamma=0.3 \\
\text { - Imaginary depth between minimum depth } h_{0}(0.5 \mathrm{~m}) \text { and berm height } h_{R} \\
\text { - Wave energy }=0 \text { where } Z \geq h_{R} \\
\text { - Lower limit of } \mathrm{h} \text { in terms of wave decay due to } \\
\text { breaking: } 0.5 \mathrm{~m}\end{array}$ \\
\hline
\end{tabular}




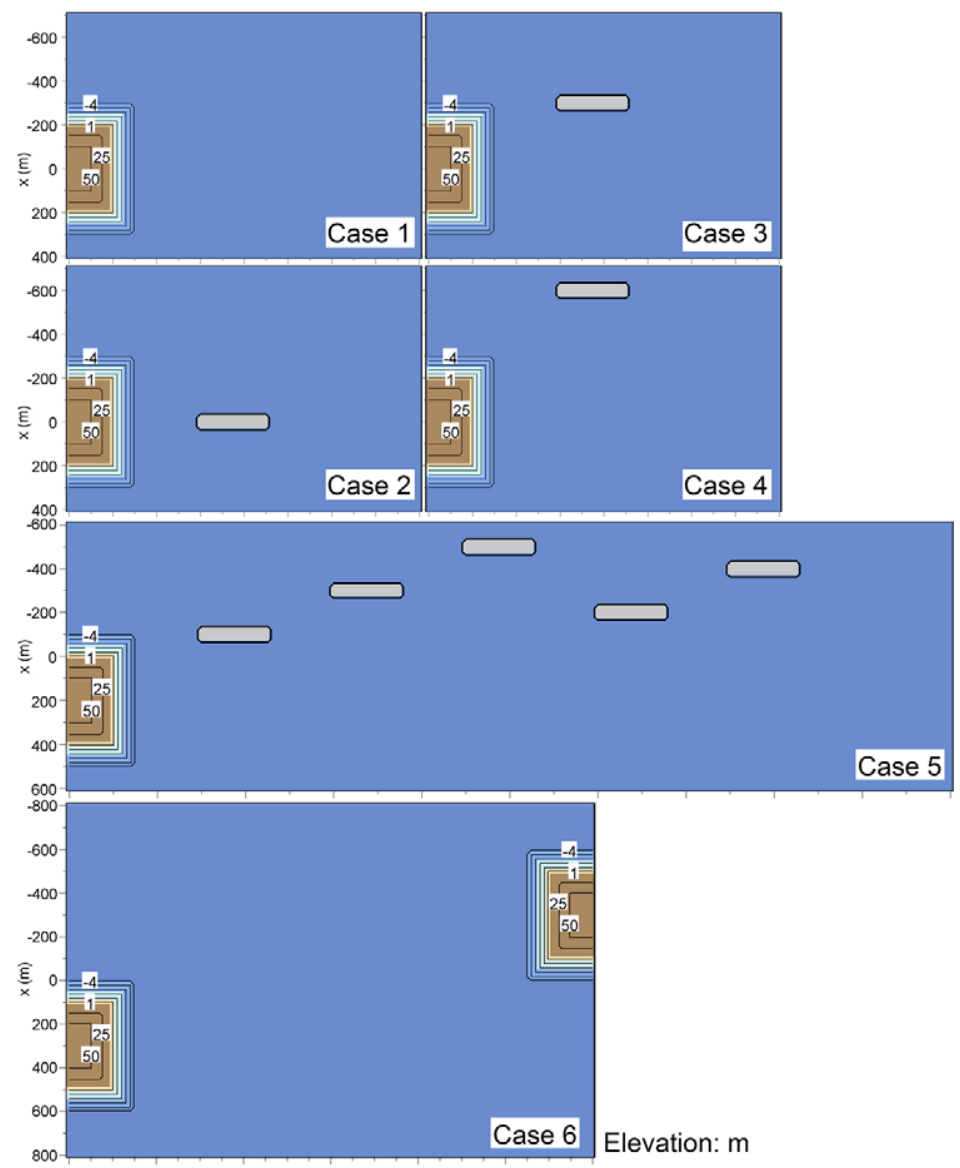

Figure 5. Arrangement of initial sand source and islands in Cases 1-6.

\section{(a) Case 3}

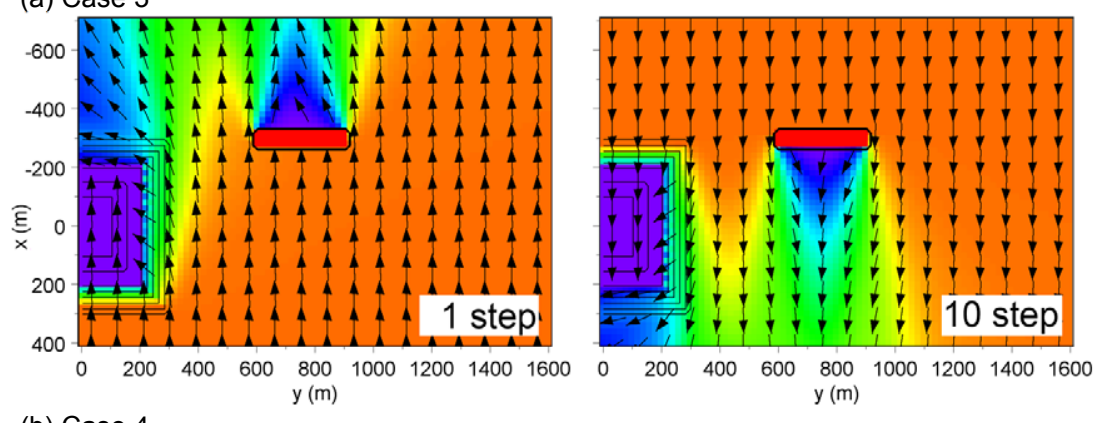

(b) Case 4

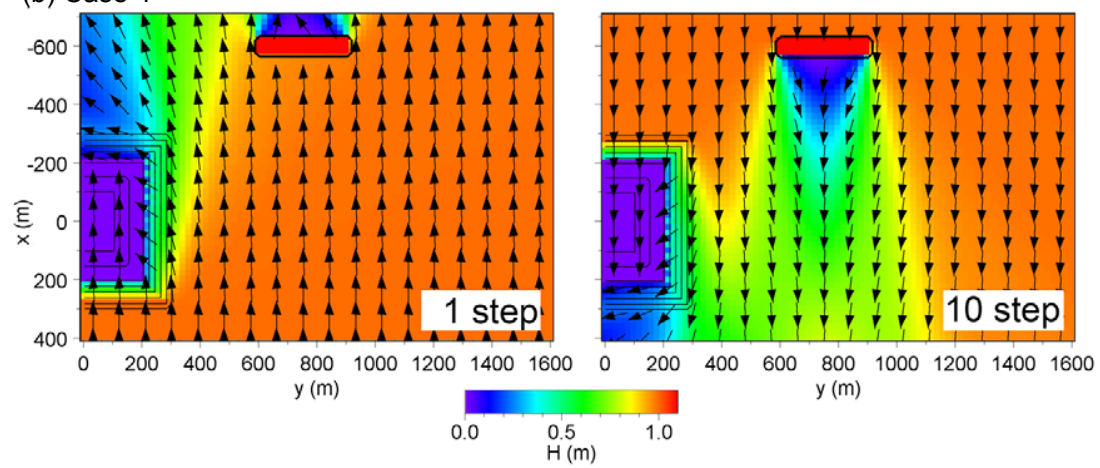

Figure 6. Wave height distribution in Cases 3 and 4. 


\section{RESULTS OF CALCULATION}

\section{Elongation of Simple Cuspate Foreland (Case 1).}

Figure 7 shows the development of the cuspate foreland when waves are incident from two opposite directions with the same probability of occurrence, similarly to that described by Serizawa et al. (2015). Because of the two directions of wave incidence (downward and upward), the sand spits began to form at the right end of the sand source by $2 \times 10^{3}$ steps, and the tips of the sand spits approached each other owing to the wave-sheltering effect of the sand spit. After $4 \times 10^{3}$ steps, two sand spits extended from the corners of the rectangular sand source and connected with each other, resulting in the formation of a triangular closed water body in the central part, and a concave shoreline was formed on both sides of the cuspate foreland. After $6 \times 10^{3}$ steps, the tip of the cuspate foreland extended to $685 \mathrm{~m}$ in the $y$-axis direction. The development of the cuspate foreland continued over time; the tip of the cuspate foreland reached 1,275 $\mathrm{m}$ after $1.4 \times 10$ steps, a triangular water body was enclosed in the nearby area of the sand source, and an extremely slender cuspate foreland extended along the $y$-axis. The calculation results explain the formation mechanism of many cuspate forelands formed at the ends of islands in Gardiners Bay on Long Island.

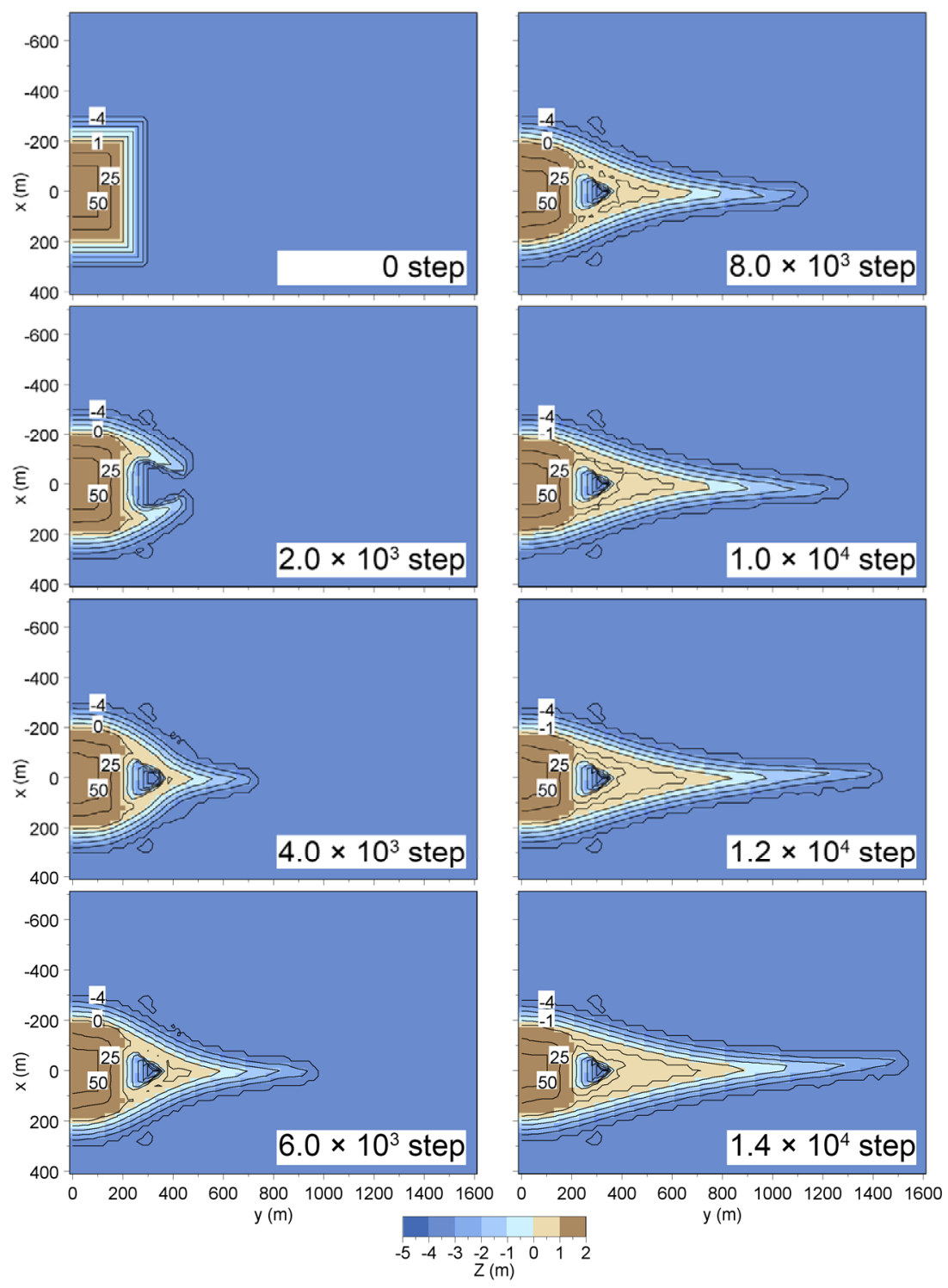

Figure 7. Elongation of simple cuspate foreland (Case 1). 


\section{Elongation of Cuspate Foreland when an Island is Located on $x$-axis (Case 2)}

Figure 8 shows the results of the development of a cuspate foreland when waves are incident from two opposite directions with the same probability, and an the island of $300 \mathrm{~m}$ length is placed between $y=600$ and $900 \mathrm{~m}$ on the $x$-axis, as shown in Fig. 8(a). In comparison with the results in Case 1 without an island, a cuspate foreland extended similarly to the result in Case 1, between the sand source and the island. After $4 \times 10^{3}$ steps, the tip of the cuspate foreland connected to the island, and since then, sand movement along the $y$-axis was partly blocked by the island. When comparing the width of the cuspate foreland at $y=600 \mathrm{~m}$ after $6 \times 10^{3}$ steps, the width was seen to increase at the connecting point because of the blockage of longshore sand transport by 0 and $50 \mathrm{~m}$ in Cases 1 and 2, respectively. The blockage of longshore sand transport in the $y$-axis direction continued, and after $1.4 \times 10^{4}$ steps, the width of the sandy beach immediately left of the island in Case 2 increased by $25 \mathrm{~m}$ compared with that in Case 1.

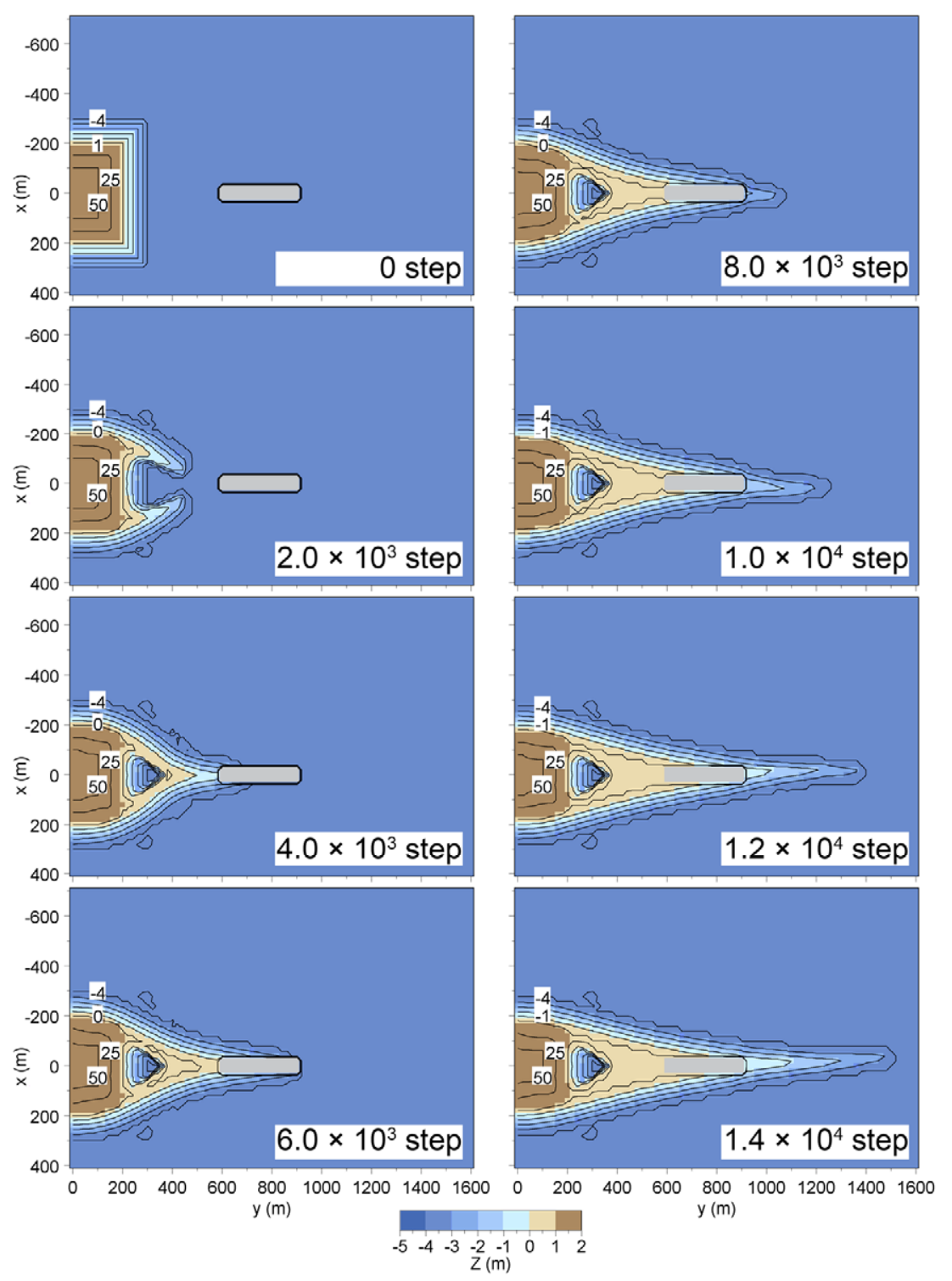

Figure 8. Elongation of cuspate foreland when an island is placed on $x=0 \mathrm{~m}$ line (Case 2).

\section{Elongation of Cuspate Foreland when an Island is Located on Line of $x=-300 \mathrm{~m}$ (Case 3)}

The island was located on the line of $x=-300 \mathrm{~m}$ in Case 3 , and the development of the cuspate foreland was investigated, as shown in Fig. 9. Because the island was placed far from the $x$-axis, waves incident from the $-x$-axis affected the wave field where the cuspate foreland was to form. Although the 
elongation pattern of this case was similar to that in Case 1 up to $2 \times 10^{3}$ steps, because the wave-shelter zone was far from the formation zone of the cuspate foreland, the tip of the cuspate foreland began to be drawn toward the lee of the island after $4 \times 10^{3}$ steps. After $6 \times 10^{3}$ steps, the direction of the tip of the cuspate foreland markedly changed, and the cuspate foreland began to connect to the left end of the island. After $8 \times 10^{3}$ steps, the cuspate foreland attached to the lee of the island, and then a small cuspate foreland started to elongate rightward from the right end of the island after $1 \times 10^{4}$ steps. Similar changes continued up to $1.4 \times 10^{4}$ steps, and the cuspate foreland extended rightward from the end of the island instead of the extension along the $x$-axis.

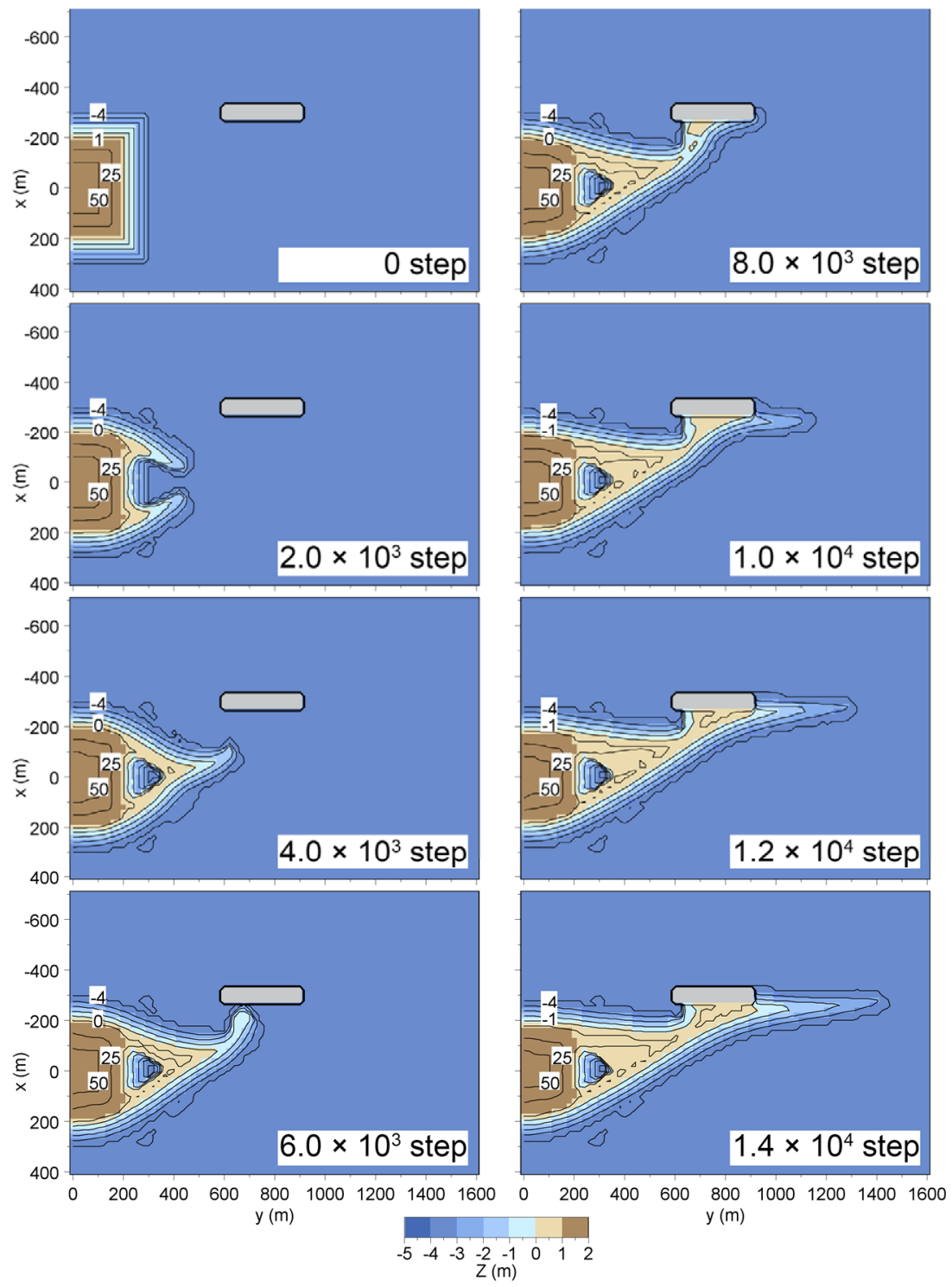

Figure 9. Elongation of cuspate foreland when an island is placed on $x=-300 \mathrm{~m}$ (Case 3).

\section{Elongation of Cuspate Foreland when an Island is Located on Line of $x=-600 \mathrm{~m}$ (Case 4)}

The island was located on the line of $x=-600 \mathrm{~m}$ in Case 4 , and the development of the cuspate foreland was investigated, as shown in Fig. 10. The island was placed at a location far from the $x$-axis, and thus, the wave-shelter zone expanded to the area where the cuspate foreland extended. After $2 \times 10^{3}$ steps, the sizes of the sand spits formed at the right end of the sand source differed from each other, with a larger size in the upper sand spit. After $4 \times 10^{3}$ steps, the tip of the cuspate foreland approached the lee of the island. After $6 \times 10^{3}$ steps, the cuspate foreland extended to the lee of the island. Although after $8 \times 10^{3}$ steps, the cuspate foreland further approached the island, it did not become close to the 
island. After $1 \times 10^{4}$ steps, another small cuspate foreland began to extend on the right side of the island. A similar change continued up to $1.4 \times 10^{4}$ steps, and the location of the cuspate foreland shifted toward the $-x$-axis.

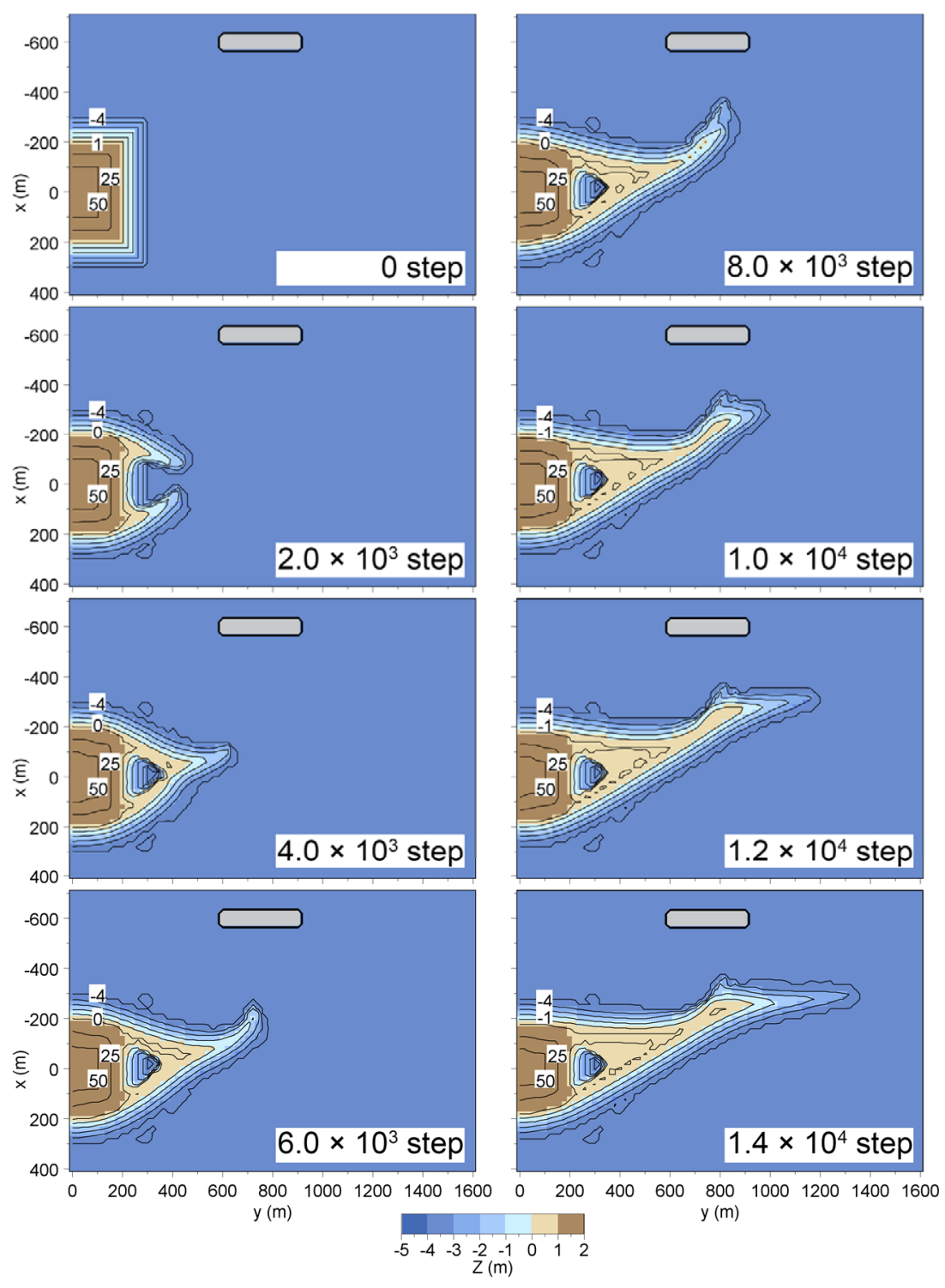

Figure 10. Elongation of cuspate foreland when an island is placed on $x=-600 \mathrm{~m}$ (Case 4).

\section{Elongation of Cuspate Foreland Connecting Five Islands (Case 5)}

The formation of the land-tied sand bar connecting multiple islands and the cuspate foreland in a shallow sea, as in the case of Hon Bip Island in Van Phong Bay in Vietnam shown in Fig. 3, was predicted. The arrangement of five islands is shown in Fig. 11(a), and the islands had different axes. As already realized by the numerical simulations of Cases 1-4, the cuspate foreland received the wavesheltering effect of an island close to the area where the cuspate foreland is extended, and then it extends toward the next island. Finally, up to $7 \times 10^{4}$ steps, each island was connected by the sand bar and a small cuspate foreland was formed from the right island. This result explains well the development of a land-tied island and the cuspate foreland around Hon Bip Island in Van Phong Bay.

The wave field in Case 5 changes alternately corresponding to the wave direction. As an example, Fig. 12 shows the wave field after $2 \times 10^{4}$ and $2 \times 10^{4}+10$ steps, when waves propagate downward and upward, respectively. With the extension of the sand bars connecting islands, the wave-shelter zone is formed on the lee of the sand bar and the islands, the wave-shelter zone is formed downcoast when 
waves propagate downward, whereas it is formed upcoast when waves propagate upward. Thus, the wave-shelter zone is formed alternately, and the sand transport toward the tip of the sand bar occurs along the exposed side of the sand bar.

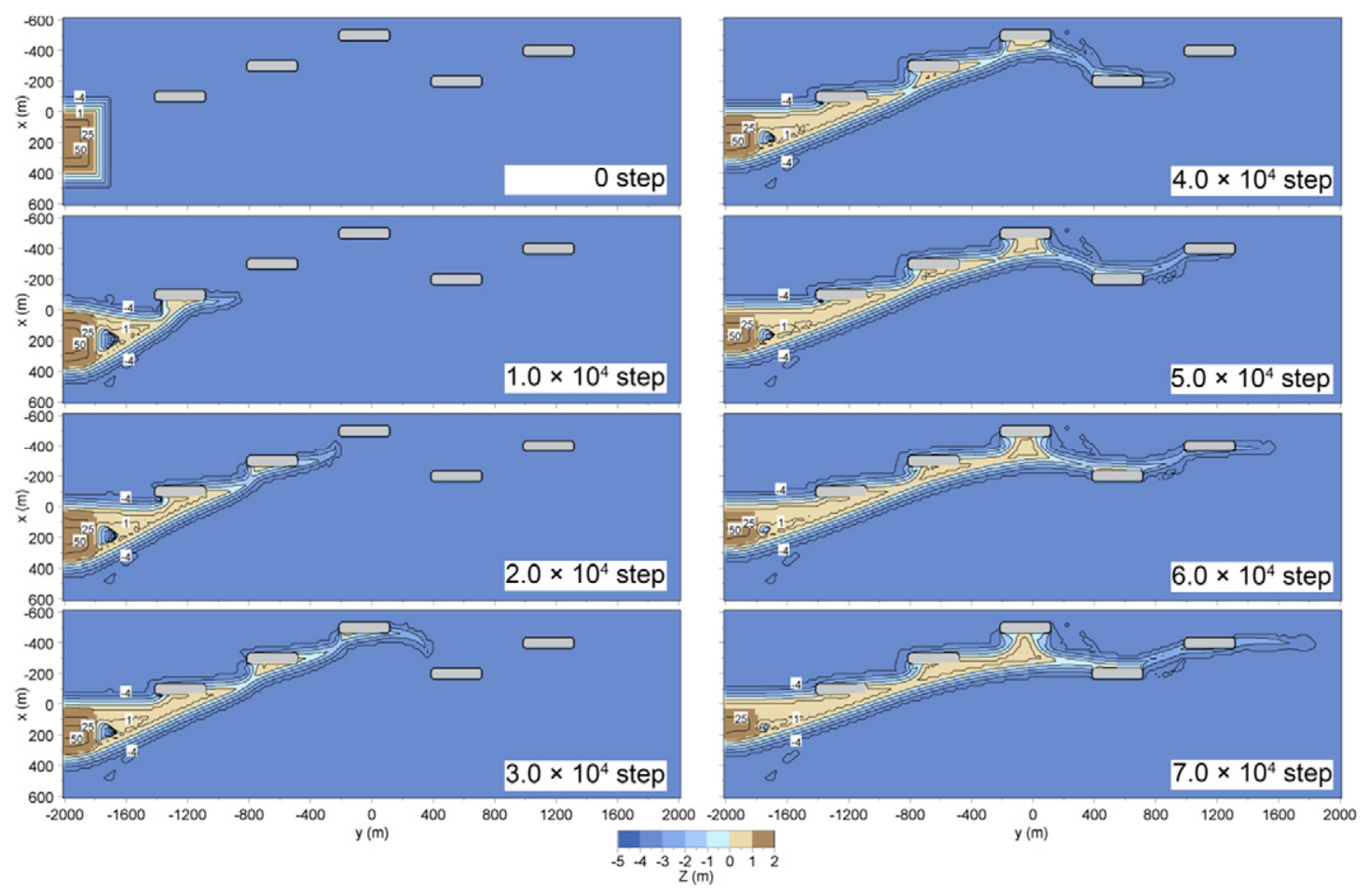

Figure 11. Extension of sand bar connecting five islands (Case 5).

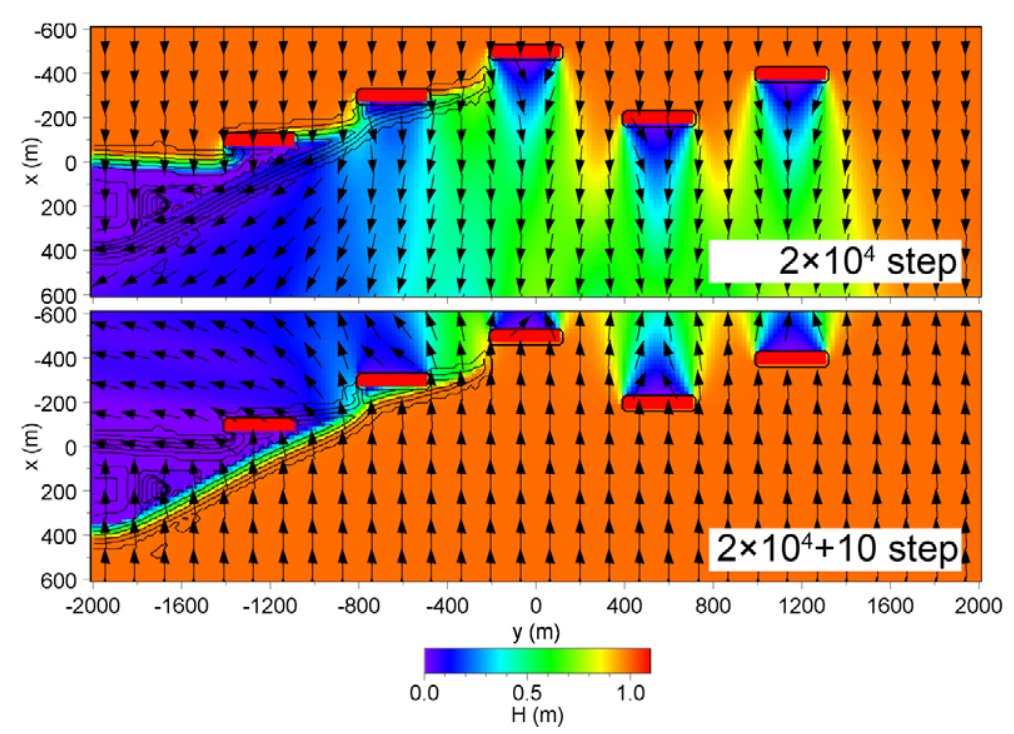

Figure 12. Wave height distribution in Case 5.

\section{Connection of Two Sand Sources by Elongation of Sand Bar (Case 6).}

In Cases 1-5, the extension of a cuspate foreland by the sand supply from a sand source was predicted, but sand may be supplied from the sand sources on both shores. In Case 6, the sand source was placed on both shores when waves are incident from two opposing directions with the same probability of occurrence, and successive topographic changes were predicted. In the model, two sand sources were placed with different centerlines. Figure 13 shows the calculation results. After $4 \times 10^{3}$ 
steps, cuspate forelands symmetrically extended from both sides, similarly to the results obtained by Miyahara et al. (2014), and then the cuspate foreland extended into both directions. After $8 \times 10^{3}$ steps, the tip of the cuspate forelands elongating from both sides began to receive the wave-sheltering effect by another cuspate foreland, and the tips began to be drawn toward each other. After $1.2 \times 10^{4}$ steps, the tips of the cuspate forelands significantly rotated and were almost connected. After $1.6 \times 10^{4}$ steps, the cuspate forelands connected to form a continuous sand bar. Over time, the smoothed shoreline of the cuspate foreland was formed and the width increased by $2.4 \times 10^{4}$ steps.

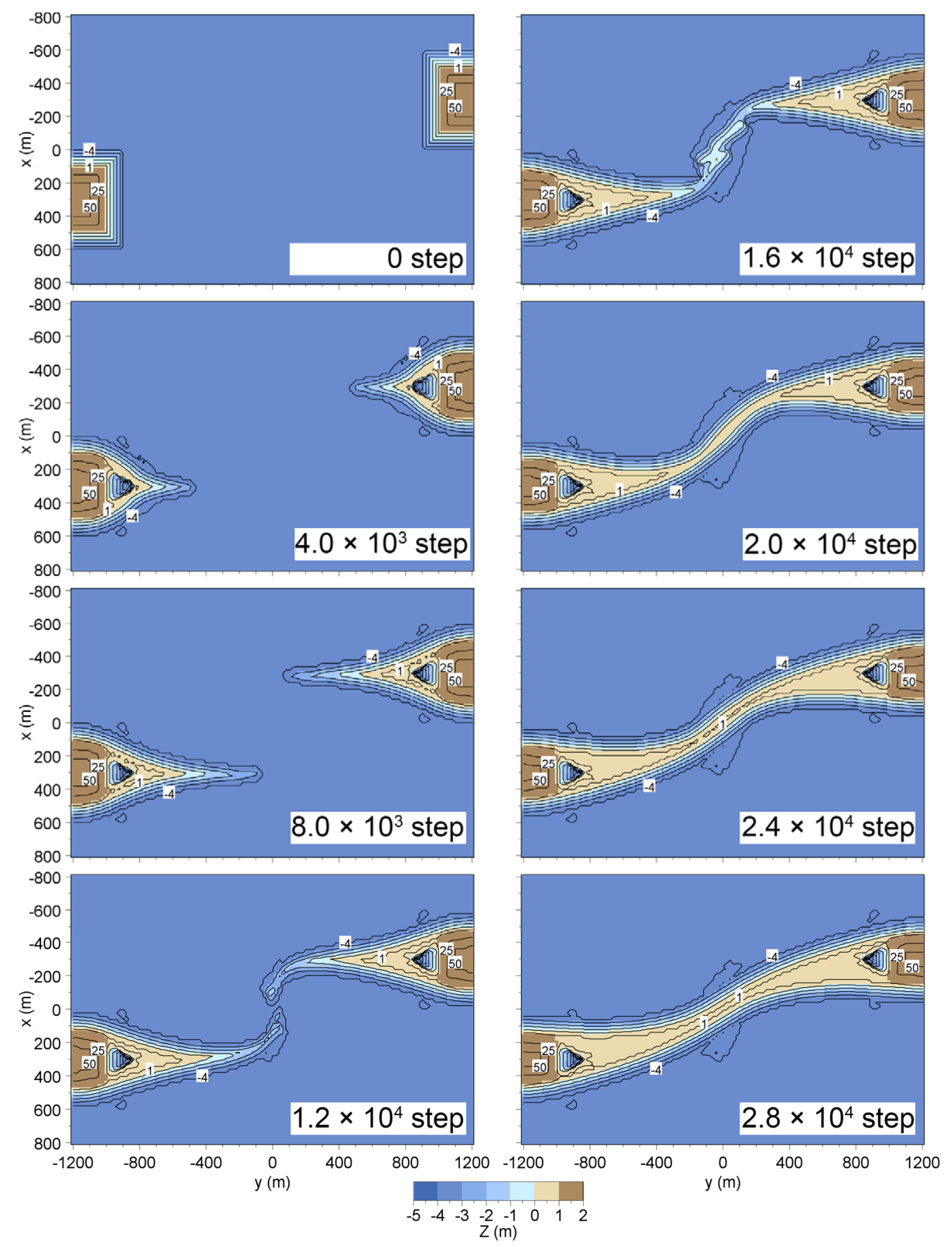

Figure 13. Connection of sand bar between two sand sources with different centerlines (Case 6). 

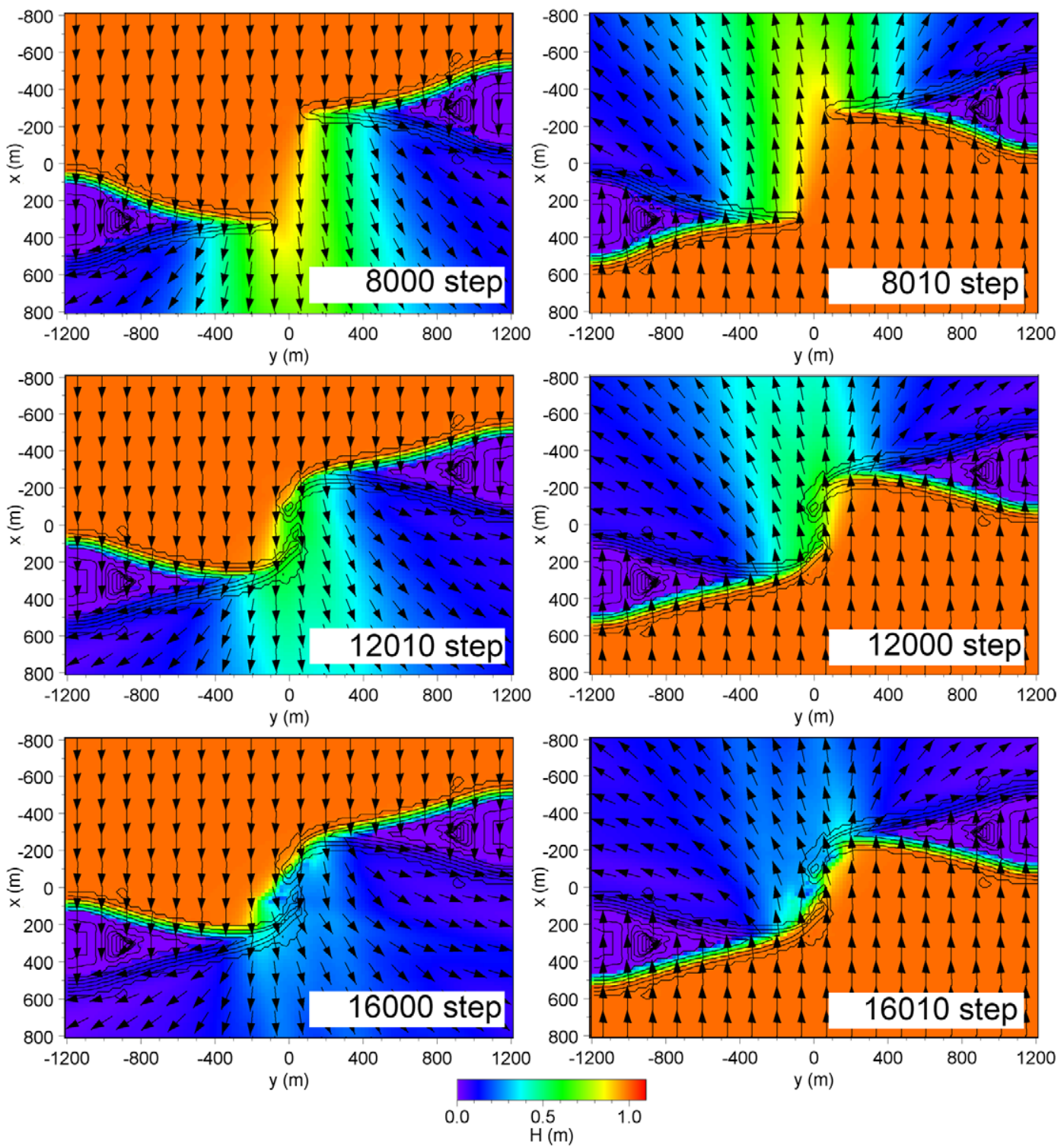

Figure 14. Wave height distribution in Case 6.

The wave field in Case 6 also changes alternately corresponding to the wave direction. Figure 14 shows the examples of the wave field after $8 \times 10^{3}$ and $8 \times 10^{3}+10$ steps, $1.2 \times 10^{4}+10$ and $1.2 \times 10^{4}$ steps, and after $1.6 \times 10^{4}$ and $1.6 \times 10^{4}+10$ steps, when waves propagate downward and upward, respectively. With the extension of the sand bars from both shores, the wave-shelter zone is formed on the lee of the sand bar. The wave-shelter zone is formed downcoast when waves propagate downward, whereas it is formed upcoast when waves propagate upward after $8 \times 10^{3}$ and $8 \times 10^{3}+10$ steps. Thus, the wave-shelter zone is formed alternately, and the sand transport toward the tip of the sand bar occurs along both sides of the sand bar. After $1.2 \times 10^{4}+10$ and $1.2 \times 10^{4}$ steps, the wave-shelter zone from one side covers the tip of the sand bar on the other side. Owing to this wave-sheltering effect, the sand bar, which had extended in the straight manner, changes its direction and it tends to extend toward the other sand bar, and the tip of the sand bars is drawn each other. After $1.6 \times 10^{4}$ and $1.6 \times 10^{4}+10$ steps, when the sand bars are about to connect each other, the downcoast of the sand bar entirely enters the wave-shelter zone of the sand bar. This wave height distribution facilitates the elongation of the cuspate foreland.

\section{CONCLUSIONS}

The morphological characteristics of two cuspate forelands located in Gardiners Bay in Long Island, New York, and Ukraine Bay in the Black Sea, and a land-tied island in Vietnam were 
investigated. The BG model was used to predict the development of a cuspate foreland, when an island is located offshore of the cuspate foreland and waves are incident from two opposite directions. It was concluded that a cuspate foreland elongates toward the lee of the island owing to the wave-sheltering effect of an island. The formation of a land-tied island when five islands and two sand sources are located on opposite shores was also predicted using the BG model. Thus, a model for predicting the elongation of a cuspate foreland in the presence of islands was developed.

\section{REFERENCES}

Ashton, A., A.B. Murray, and O. Arnault. 2001. Formation of coastline features by large-scale instabilities induced by high-angle waves, Nature, 414, 296-300.

Ashton, A., and A.B. Murray. 2006. High-angle wave instability and emergent shoreline shapes: 1. Modeling of sand waves, flying spits, and capes, J. Geophys. Res., Vol. 111, F04011, doi: 10.1029/2005JF000422.

Bagnold, R.A. 1963. Mechanics of marine sedimentation, Hill, M.N. ed. In The Sea, Vol. 3, Wiley, New York, 507-528.

Dally, W.R., R.G. Dean, and R.A. Dalrymple. 1984. A model for breaker decay on beaches, Proceedings of $19^{\text {th }}$ International Conference on Coastal Engineering, ASCE, 82-97.

Goda, Y. 1985. Random Seas and Design of Maritime Structures, University of Tokyo Press, Tokyo, p. 323.

Mase, H. 2001. Multidirectional random wave transformation model based on energy balance equation, Coastal Eng. J., JSCE, 43(4), 317-337.

Miyahara, S., T. Uda, and M. Serizawa. 2014. Prediction of formation of land-tied islands, Proceedings of $34^{\text {th }}$ International Conference on Coastal Engineering, ASCE, 1-14.

Ozasa, H., and A.H. Brampton. 1980. Model for predicting the shoreline evolution of beaches backed by seawalls, Coastal Eng., 4, 47-64.

Scheffers, A.M., S.R. Scheffers, and D.H. Kelletat. 2012. The Coastlines of the World with Google Earth, Coastal Research Library, Vol. 2, Springer, New York, p. 293.

Serizawa, M., T. Uda, T. San-nami, and K. Furuike. 2006. Three-dimensional model for predicting beach changes based on Bagnold's concept, Proceedings of $30^{\text {th }}$ International Conference on Coastal Engineering, ASCE, 3155-3167.

Serizawa, M., T. Uda, and S. Miyahara. 2012. Prediction of development of sand spits and cuspate forelands with rhythmic shapes caused by shoreline instability using BG model, Proceedings of $33^{\text {rd }}$ International Conference on Coastal Engineering, ASCE, sediment.35, 1-11.

Serizawa, M., T. Uda, and S. Miyahara. 2015. Model for predicting formation of a cuspate foreland, Coastal Sediments '15, CD-ROM, No. 65, 1-14.

Uda, T., M. Gibo, T. Ishikawa, S. Miyahara, T. San-nami, and M. Serizawa. 2013. Change in carbonate beach triggered by construction of a bridge on Irabu Island and its simulation using BG model, Asian and Pacific Coasts 2013, Proc. $7^{\text {th }}$ International Conf., 24-32.

Uda, T., M. Serizawa, and S. Miyahara. 2014. Development of sand spits and cuspate forelands with rhythmic shapes and their deformation by effects of construction of coastal structures (Chap. 19), pp. 419-450, in 'Computational and Numerical Simulations' Awrejcewicz, L. ed., INTEC.

Zenkovich, V. P. 1967. Processes of Coastal Development, Interscience Publishers, New York, p. 751. 